\title{
El culto a San Benito de Palermo, elementos de la herencia africana en El Salvador
}

José Heriberto Erquicia Cruz

jose.erquicia@utec.edu.sv

Martha Marielba Herrera Reina

Dirección de Investigaciones y Escuela de Antropología

Universidad Tecnológica de El Salvador

\section{Resumen}

Numerosos elementos culturales en El Salvador tienen su origen en un pasado que poco a poco se va revelando. Tal es el caso del culto a San Benito de Palermo, que se encuentra en la zona oriental del país. Esta región, desde la época colonial estuvo conformada por diversas comunidades étnicas que le dieron forma a muchas expresiones que se practican hoy en día. Este articulo muestra cómo la identidad y los elementos culturales de los afrodescendientes se mantienen vigentes en la actualidad en el país.

Palabras clave: Religiosidad popular, afrodescendientes, relaciones étnicas, asimilación cultural, San Benito de Palermo.

\section{Abstract}

Many cultural elements in El Salvador have their origin in a past that slowly reveals itself, as in the case of the cult of San Benito de Palermo that is located in the east of the country. This region, from the colonial period consisted of various ethnic communities that have shaped many expressions that are practiced today. This article shows how the identity and cultural elements of afro-descendants still exist today in the country.

Keywords: Popular religiosity, african descent, ethnic relations, cultural assimilation, San Benito de Palermo.

\section{Introducción}

La diversidad étnica y cultural del actual territorio salvadoreño es el resultado de la fusión de elementos de los distintos grupos étnicos que cohabitaron en la región. Para el caso de la zona oriental, en departamentos como
Usulután y San Miguel, se mantienen vigentes prácticas y tradiciones de los afrodescendientes que se asentaron en dicha zona, esto debido a la cantidad de haciendas añileras y ganaderas que adquirían esclavos negros y que tenían también como sus trabajadores a los hijos de estos nacidos en las mismas haciendas. De esta forma, la religiosidad 
se impone creando un abanico de creencias que fueron adoptadas y apropiadas por los afrodescendientes de esa zona, misma que en la actualidad conserva ese mundo religioso creado desde la época colonial.

La investigación permite mostrar que la identidad y los elementos culturales de los afrodescendientes se mantienen vigentes en nuestro país. Esta investigación es parte de las "etnografías de rescate" que pretenden el salvataje, la puesta en valor y la difusión de las tradiciones, las prácticas, los ritos, los conocimientos del presente y los ancestrales de las diversas comunidades que coexisten en El Salvador del presente.

El abordaje de la diversidad étnica en El Salvador ha sido un tema de bajo perfil, pues por generaciones se ha dicho y sustentado, desde el Estado y las instituciones, que tal diversidad no existe, pues "todos somos mestizos". Sin embargo, no se puede obviar la existencia de la diversidad de grupos étnicos que han habitado a través de los siglos en el actual territorio salvadoreño. Así, los grupos afrodescendientes aparecen desde el siglo XVI a la llegada de los europeos al territorio nacional. Los censos coloniales no dejan mentir sobre la clara e importante presencia de esclavos negros, negros libres, mulatos, pardos, zambos, panunes y otras categorías de ascendencia africana. Dicha presencia se negó por parte de los gobernantes e intelectuales liberales de finales del siglo XIX e inicios del XX, construyendo un Estado salvadoreño "libre de negros", en una clara negación a su pasado multiétnico y a una idealización del "blanqueamiento de las razas", volviéndose una sociedad racista en aras del progreso y la modernización.

El objetivo general de la investigación fue registrar las expresiones religiosas y los elementos identitarios afrodescendientes de la fiesta a San Benito de Palermo a través del método etnográfico y las fuentes históricas en la zona oriental de El Salvador. Este se vincula con las preguntas problema que orientaron esta investigación. Estas son: a) ¿Cuáles son los orígenes del culto a San Benito de Palermo en la zona oriental de El Salvador? b) ¿Qué grupos étnicos influyeron en la práctica a San Benito de Palermo? c) ¿Cuáles son los motivos del cambio de patronazgo en Ereguayquín? d) ¿Qué cambios ha tenido el culto a San Benito de Palermo desde sus orígenes hasta la actualidad? e) ¿Cuáles son los elementos de los grupos afrodescendientes en las prácticas vigentes en el culto a San Benito de Palermo?

La metodología empleada estuvo bajo el enfoque cualitativo, donde el método comparativo y el etnográfico permitieron tener un acercamiento de primera mano de los datos que asintieron la comprensión del fenómeno estudiado. En cuanto a las técnicas operativas de la investigación cualitativa, se empleó la entrevista semiestructurada a los practicantes y creyentes del culto, así como la observación directa con participación moderada, pues se trata "de observar reflexivamente y críticamente los procesos sociales y no de condenar o elogiar" (Sánchez, 2001). En este aspecto, se utilizaron recursos como cámara fotográfica digital, cámara de video, grabadora y diario o libreta de campo.

\section{Cultos cristianos de africanos esclavizados y afrodescendientes en América}

La cristianización en África se ubica en el Reino del Congo, a mediados del siglo XV y a inicios del XVI, cuando los portugueses buscaban romper el monopolio árabe de las especias, que surtía el Mediterráneo. En esas fechas se construyeron iglesias, entre ellas las de Nuestra Señora de las Victorias, Santiago el Mayor, Nuestra Señora del Rosario, Concepción, Santa Cruz, San Juan Bautista, San Miguel Arcángel y la Santa Isabel. Entre las órdenes religiosas que se asentaron en África estuvieron la Orden de Cristo, carmelos, jesuitas y capuchinos, quienes se dieron a la tarea de evangelizar esas tierras (Cáceres, 2008), en donde la principal actividad de los misioneros era el bautismo, tanto de los lugareños como de los esclavos que desde regiones más lejanas eran llevados a las costas y posteriormente obligados a migrar a lugares lejanos.

Establecidas las colonias en América, la necesidad de esclavos se hizo mayor, eso trajo consigo la idea de cristianizarlos, esta era una manera de incorporarlos e integrarlos de forma dócil al sistema productivo. Para ellos se crearon normas de evangelización que emanaron de cédulas reales. De estas, la más temprana aparece en el año 1537, donde se declara que los que han de ir a la doctrina cada día son los indios, negros y mulatos que sirven en las casas ordinariamente. Esta debía de prorrogarse de por 
vida, es decir, abarcaba a toda la población negra y mulata que estaba asentada en tierras americanas. A ella debían asistir los negros y mulatos durante una hora los domingos y días de fiesta, así mismo, se establecieron como lugares de catequesis (preferentemente) parroquias en las ciudades y ermitas o iglesias de las haciendas y los ingenios en las zonas rurales, entendiéndose que estas eran las zonas con mayor población negra y mulata debido a las actividades económicas en las que participaban, aunque una de los limitantes al inicio fue la lengua que hablaban los esclavos; posteriormente, los descendientes de estos ya no tendrían ese problema (Vila, 2000).

Según Vila (2000), estas formas de llevar la misión de salvación de almas de los no cristianos en la época colonial traía consigo la enseñanza de los sacramentos, como: bautismo, penitencia, eucaristía, confirmación, extrema unción, matrimonio y orden sacerdotal, es este último el único sacramento vedado a los negros hasta fines del siglo XVIII, como consecuencia del Concilio de Trento, que prohibió ordenar a gente de procedencia ilegítima y que tuvo repercusión en el segundo Concilio Limense. ${ }^{1}$ que cierra la puerta del sacerdocio a indios y mestizos $y$, por supuesto, a negros y mulatos. Finalmente, se les permite su ingreso al sacerdocio.

Cada uno de estos jugaron un papel importante en la población; además, debían tener conocimiento del padrenuestro, credo, mandamientos de la ley de Dios y de la Iglesia, y los pecados capitales; también importante era la participación en las devociones, fiestas y cofradías, que suponían para ellos (negros y mulatos) un espacio de libertad y una forma de expresar sentimientos que estaban más acordes con su cultura, con todo esto se les inculcó la idea de que a través de esto podían llegar a la salvación de sus propias almas (Vila, 2000). De una u otra forma, los mecanismos de cristianización en América lograron que tanto indios como esclavos negros y sus descendientes se convirtieran en fieles bajo una advocación de un santo o de un misterio. Los africanos lograron, con el paso del tiempo, relacionar la nueva religión con las creencias de sus antepasados. Esto paulatinamente dio origen a cultos y religiones sincréticas que se mantienen hasta hoy en día.

\section{San Benito de Palermo}

La devoción a San Benito de Palermo tiene a sus fieles en diversos países como España, Italia, México, Guatemala, El Salvador, Nicaragua, Venezuela, Argentina, Colombia y otros países de América Latina. Según las crónicas franciscanas ${ }^{2}$ , se dice que San Benito de Palermo nació en un pueblecito de Mesina (Sicilia, actualmente isla mediterránea que pertenece a Italia). Sus padres, esclavos manumitidos, aunque oriundos de moros, eran muy buenos cristianos. Caritativos con los pobres, fieles cumplidores de las leyes de la Iglesia, estaban de administradores de un rico señor, que les prometió dar libertad a sus hijos si los llegaban a tener; desde joven las curaciones milagrosas, la multiplicación de los alimentos y el discernimiento de los espíritus vinieron a ser en él familiares y comunes. Recibió los últimos sacramentos, y el 4 de abril de 1589 expiró a la edad de 63 años. Su culto se difundió ampliamente y vino a ser el protector de los pueblos negros. Fue canonizado por Pío VII el 24 de mayo de 1807 (Franciscanos, 2011).

En este caso, las imágenes sagradas y la religiosidad popular de los iconos adoptados y adaptados en la comunidad afrodescendiente se identificaron con el origen del santo, es decir, toman su imagen y la adaptan a su realidad. Entre los aspectos humanos que los identifican encontramos, además del color de la piel, los trabajos que tuvo que realizar en el campo, ya sea en el pastoreo o la agricultura, mismos que los esclavos en América tenían que realizar en las haciendas o ingenios donde los habían llevado. En el caso de México, este culto se ubicaba en el siglo XVI, cuando se funda la Cofradía de San Benito; se constituyó por fieles de ambos sexos, sin importar su arte u oficio ni su calidad de libres o de esclavos. Reunidos alrededor de la figura del santo patrón, escuchaban misas y sermones, rezaban responsos por el alma de sus hermanos difuntos, aprendían el catecismo, celebraban sus fiestas dentro del calendario litúrgico, recibían los sacramentos, realizaban

\footnotetext{
Concilio realizado en Lima, a finales de la década de 1560, en donde siempre se mantiene la idea de la evangelización de los indios y esclavos, legisla sobre la organización, reforma visitas de las doctrinas; en especial indica y da medios para combatir la idolatría. Fueron convocados los obispos de Charcas, Paraguay, Popayán, la Imperial, Santiago de Chile, Cuzco, Quito, Panamá y Nicaragua.

2 Tomado del sitio web: http://www.franciscanos.org/santoral/benitopalermo.htm
} 
actividades religiosas y adoptaban conductas y actitudes dirigidas por un sistema de valores hispánicos y católicos (Roselló, 2008).

Por un lado, el ingreso a la cofradía les permitía tener derechos que les brindaban seguridad material y espiritual, y por otro, tenían obligaciones que les daban oportunidad de sociabilizar, dar santa sepultura y organizaría misas y responsos que aseguraban la salvación directa del alma, se comprometían a cuidar de los huérfanos y las viudas de todos los miembros de la corporación. Esta les permitía discutir problemas comunes a su condición étnica, el acceso a servicios de asistencia social para ellos y sus familiares, la posibilidad de interactuar socialmente con otras corporaciones, así como la adquisición de una personería jurídica y oficial. También se evidencia el aspecto festivo de la tradición religiosa; nos dice que los tambores de cuero de buey, las sonajas, los cantos, bailes, risas y carcajadas solían acompañar las procesiones de sujetos que no podían olvidar la herencia de su pasado africano (Roselló, 2008).

Es la existencia de estos espacios asociativos, y no la mera presencia de población de origen africano, la que favoreció y dio continuidad a sus distintas manifestaciones. Esta situación de representaciones culturales afrodescendientes puede ser que se repita en varios países donde, en la actualidad, se les ha negado e invisibilizado, es decir, donde su presencia está vigente, sin que la población tenga el conocimiento de sus orígenes.

En todos los casos, los africanos y afrodescendientes se reunieron en torno a un santo y a su respectiva cofradí. En palabras de Gutiérrez (2011):

Quedaron estructuradas en cierto modo siguiendo líneas tribales o étnicas, en ello influyó el ambiente social de la pureza de sangre y la estratificación por el color que dominaba en la sociedad, así encontramos entre sus miembros a negros, mulatos, pardos, esclavos y libres pertenecientes a diferentes etnias africanas, preferentemente varones, aunque hubo cofradías que admitieron mujeres. Las cofradías, según línea étnica, fueron particularmente preferidas en el siglo XVI (Gutiérrez, 2011, p. 2).
Y agrega que es:

Lógico que sus miembros fueran esclavos o libres que tuvieran cierto nivel socioeconómico como los esclavos domésticos, jornaleros o conocedores de algún oficio debido a que eran los únicos con algún tiempo libre y con recursos suficientes para dedicarse activamente a estas prácticas religiosas (Gutiérrez, 2011, p. 3).

Entonces, en este caso, los miembros de la cofradía tenían un estatus distinto al de los demás. Sin embargo, no se negaba el acceso a los demás a ser partícipes de la festividad en honor al santo que veneraban.

Si bien la religiosidad y las creencias de los africanos y afrodescendientes se fusionó en algún momento, en la actualidad esas expresiones religiosas y festivas son las que han mantenido tradiciones que pudieron haberse originado en la época colonial y que se mantienen vigentes, además de otros cultos a imágenes relacionadas con estos grupos étnicos, por medio de cofradías que en su momento fueron las instituciones que les permitieron reforzar su identidad en un entorno geográfico distinto al suyo, en una tierra a la que no pertenecían y a la que poco a poco tuvieron que adaptarse y sobrevivir, sin olvidar sus raíces culturales. Tal es el caso de la celebración a San Benito de Palermo en la zona oriental de El Salvador, territorio que anteriormente estuvo poblado por los africanos y mulatos que trabajaban en las haciendas que producían añil, en donde se reunían y convivían en torno a un santo de origen africano con el que se identificaban y en el que se reflejaba su condición de campesinos y de grupo excluido por la sociedad en la que estaban inmersos.

\section{De las cofradías legales y de las clandestinas: cultos públicos y privados}

Los espacios donde se realizan cultos religiosos son diversos. Estos pueden tener sus variantes de acuerdo con la geografía, grupo étnico que lo práctica, año de su fundación y apropiación del santo venerado, por mencionar algunos ejemplos. Este es el caso del culto a San Benito de Palermo en la zona oriental de El Salvador, el cual presenta particularidades en cada uno de los lugares recorridos 
durante esta investigación que vale la pena mencionar. Solo abordaremos cuatro de ellos; sin embargo, todos estos forman parte de una región que en la época colonial correspondía al Curato de Ereguayquín (figura 1). Esta geografía sagrada establecida en ese periodo se mantiene vigente en la actualidad.

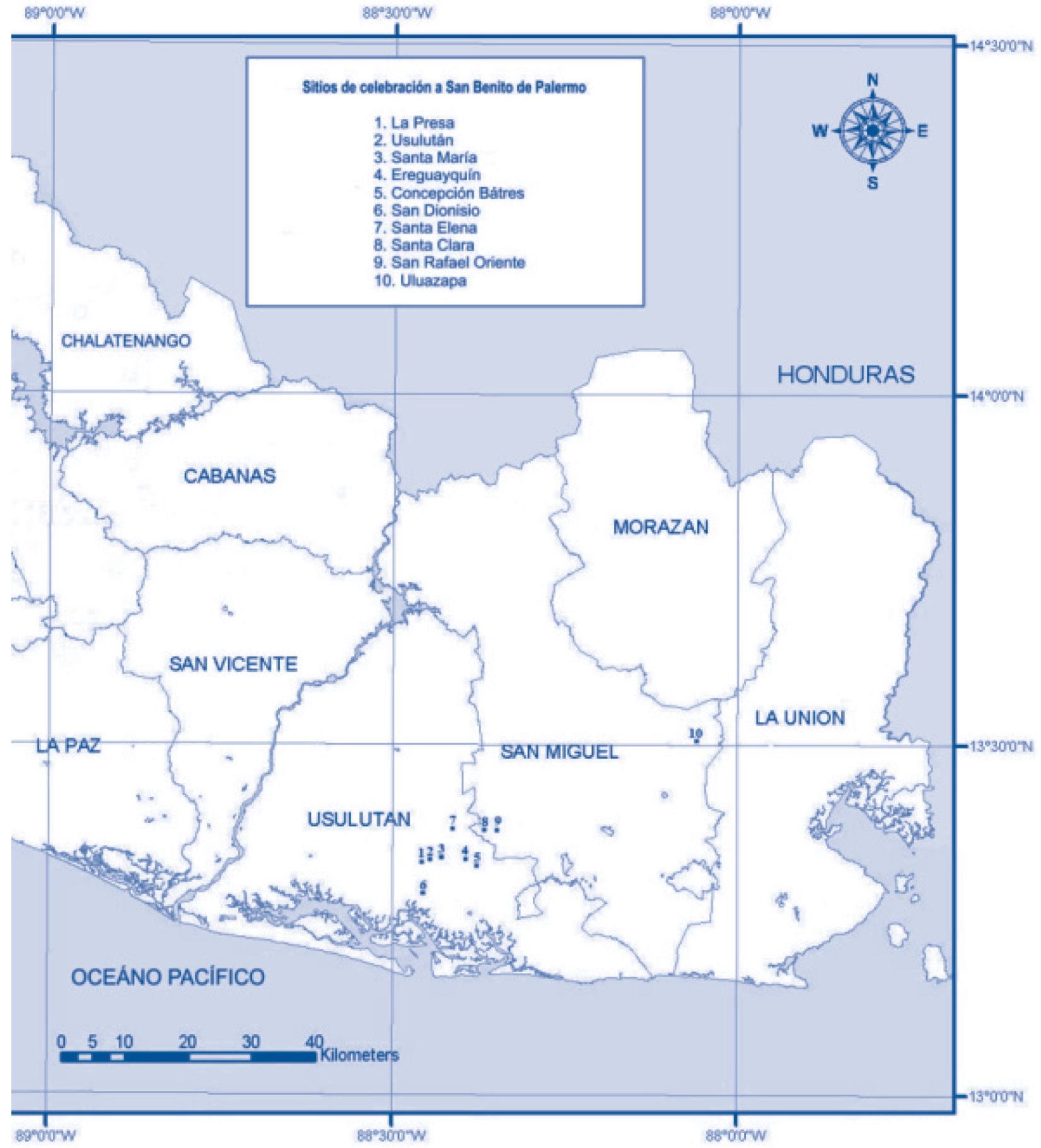

Figura 1. Mapa de ubicación de sitios que celebran a San Benito de Palermo en el oriente del territorio salvadoreño. Elaborado basado en el trabajo de campo de la investigación por Heriberto Erquicia, 20011. En: Mapa de Michigan State University, Projection: Lambert Conformal Conic, Geographic Coordinate System: North American Datum, 1983. 
Los grupos afrodescendientes que mantuvieron en la época colonial la tradición del culto a San Benito de Palermo, santo de antepasados africanos, vieron en la música y la danza una forma de expresión de la identidad heredada de sus antepasados, aquella fue adaptada a las condiciones de vida del nuevo lugar de residencia. Desde el inicio del período colonial, las danzas de los negros acompañaban los cortejos religiosos y también la celebración de las fiestas reales, en donde los negros tocaban sus instrumentos musicales flautas y sobre todo tambores-, distinguiéndose los grupos por sus ritmos específicos y su propio estilo (Bernard, 2001, p. 57). Por ello, apunta Giménez (2010), "tenían a la danza como una forma de comunicación de su concepción religiosa, alegórica a sus condiciones de vida y medio de sociabilidad de la comunidad" (Giménez, 2010, p. 1). En este sentido, las prácticas religiosas fusionadas con elementos no cristianos les daba un sentido de pertenencia e identidad como grupo social excluido. En un inicio podría haberse tratado de reuniones que realizaban los negros esclavizados que laboraban en las diferentes plantaciones de añil, caña de azúcar y tabaco de las haciendas cercanas al antiguo curato de Ereguayquín, manteniendo siempre lo subalterno como una forma de expresión y resistencia social, que con el paso del tiempo fue perdiendo ese sentido. Sin embargo, en la actualidad, aunque es una tradición religiosa aceptada por la institución de la Iglesia católica, los remanentes se mantienen vigentes en la práctica, aunque se haya perdido con el tiempo el verdadero origen de esta tradición, que solo en contados casos llegó a funcionar como una cofradía de negros y, en otras, como agrupaciones clandestinas.

El establecimiento de esa institución religiosa no se encuentra fácilmente en los registros documentales en la región centroamericana. Lo poco que se localiza de las cofradías a San Benito de Palermo, para el caso de El Salvador, nos relatan que en el año:

1651, ya existía una cofradía en el monasterio franciscano de San Salvador. Veinte años más tarde, fue fundada otra en una propiedad cerca de Zacatecoluca, y pronto otras dos fueron reportadas funcionando en la vecindad de San Diego de la Gomera, incluyendo a otra clandestina en el cercano ingenio dominico [éstas últimas vecindades de la Gomera y el ingenio Dominico se encuentran en Guatemala]. Los encargados de esta propiedad se quejaron de que las personas esclavizadas se habían negado a informar todo lo relacionado con dicha cofradía. La preocupación de los frailes provino del miedo de la Iglesia de que la ausencia de supervisión de una cofradía podría ser naturalmente un asilo para la práctica de rituales poco ortodoxos, como probablemente sucedió. Esta cofradía "ilegal", en otras palabras, representaba el rechazo, $o$ al menos la resistencia, al orden colonial prevaleciente, como lo fueron las actividades de los cimarrones (Lokken y Lutz, 2008, p. 35).

En este punto, valdría la pena recordar que también empleaban creencias que hacían que la sociedad viera con malos ojos esa fusión de elementos de creencias no cristianas que estaban presentes en la religiosidad de los negros esclavizados y libertos.

Por otra parte, en los documentos de las Visitas Pastorales, retomados por Loucel (2011), refieren a que,

en 1670 existió una cofradía fundada en honor a San Benito de Palermo, a quien también Ilamaban moro o el negro, por el color de su piely ascendencia africana y la cual fue fundada en el Convento de Santo Domingo por Luis de Figueroa, indio alcalde de dicha cofradía y por Manuel Hernández y Juan Ventura, negros (Loucel, 2011, p.7).

Por otro lado, Santiago Montes menciona que el arzobispo de Guatemala Pedro Cortez y Larráz documenta, en el siglo XVIII, que la cofradía de San Benito de Palermo en la Parroquia de Ozulutan y sus anexos contaba con un capital de 309 pesos (Montes, 1976, p. 54).

Así, se observa entonces que probablemente las primeras asociaciones mencionadas anteriormente estaban relacionada al cimarronaje, mientras las segundas otorgan un estatus legal distinto de una cofradía fundada por los grupos étnicos y reconocida por la institución religiosa. Sin embargo, cabría la posibilidad de que muchas de las funciones de los miembros de estas asociación fueran similares a los que se tenían en la cofradía de Veracruz en México y otros países con similares características étnicas, religiosas, económicas y políticas.

Estas organizaciones, propias de este grupo étnico, llevan a verificar que desde el siglo XVII las ideas del uso de espacios 
permitidos y clandestinos permitían la identificación y socialización con los diversos grupos étnicos que convivían en ese territorio. Estos espacios ofrecían hasta cierto punto un poco de libertad, que implicaba resistencia al orden social impuesto (Giménez, 2010, p. 8).

Por una parte, tenemos lo público en cuanto al culto mismo del santo negro; era permitido por la Iglesia por el mismo hecho de estar legalizada la organización y la protección a la imagen. Esto implica la puesta en práctica de los rituales permitidos por la Iglesia, y que poco a poco fueron adquiriendo elementos culturales de los afrodescendientes; por otra, el ámbito privado y las practicas "ocultas" permitieron que se mantuvieran elementos tradicionales de la cultura africana. No hay un momento que se pueda identificar como el punto de unión de ambas. Sin embargo, estas se evidencian en los remanentes religioso-culturales en la actualidad; por ejemplo, la religiosidad, la música y los bailes.

En todos los casos del culto en la región investigada, se relatan historias de actividades cotidianas. Sin embargo, por el entorno y la representación de las imágenes actuales, es más representativo de la labor agrícola propia de la región. Recuérdese que, desde la época colonial, los africanos y afrodescendientes estaban ligados a estas actividades económicas. En este sentido, hay un vínculo directo con las mismas formas de vida. Entonces, la población adquirió con el tiempo un símbolo propio, al que adaptaron según sus necesidades y la concepción de la vida. Entonces, el San Benito de Palermo es el campesino mismo, el que sana de enfermedades a niños y adultos, donde también es importante tomar en cuenta las condiciones sociales, culturales, económicas y políticas que dieron forma a estas expresiones.

En relación con la organización, llega la hora ritual donde son los devotos y fieles de San Benito de Palermo los que se encargan de pagar por los favores recibidos por medio de la Danza de los Tabales, ${ }^{3}$ Ios acompaña el grupo musical; que es imprescindible en la tradición, en este caso, es la Chanchona. Entonces, este es un trabajo colectivo en donde todas las partes involucradas aportan para mantener viva la tradición religiosa, misma que es parte de su patrimonio inmaterial local, que se ha mantenido vigente en el tiempo y que, según la mayordoma, se va transmitiendo de generación en generación.

Las experiencias que se viven dentro de la tradición son el resultado de repetir aspectos pasados, ya sean reales o inventados, que pueden ser innovados o reinventados, siempre y cuando estas modificaciones respondan a elementos similares que permitan la continuidad social. Esta tradición busca inculcar valores y normas de comportamiento por medio de la repetición dentro del contexto social en el que surgió. Quizá en este último elemento no estén tan claros con los diferentes grupos étnicos que con el tiempo fueron dando forma al culto a San Benito de Palermo y, a su vez, a la Danza de los Tabales. Cada uno de los lugares registrados en esta investigación presentan particularidades en cuanto a peticiones y exvotos, ya sea en espacios públicos o privados:

Tabla 1. Resumen de elementos religiosos del culto a San Benito de Palermo

\begin{tabular}{|c|c|c|c|c|c|}
\hline $\begin{array}{c}\text { Población } \\
\text { donde se } \\
\text { practica }\end{array}$ & $\begin{array}{l}\text { Principal } \\
\text { lugar de } \\
\text { culto }\end{array}$ & $\begin{array}{l}\text { Fechas } \\
\text { rituales }\end{array}$ & $\begin{array}{l}\text { Significado del } \\
\text { culto }\end{array}$ & $\begin{array}{l}\text { Elementos } \\
\text { asociados a la } \\
\text { imagen }\end{array}$ & $\begin{array}{c}\text { Elementos } \\
\text { rituales }\end{array}$ \\
\hline $\begin{array}{l}\text { Ereguayquín, } \\
\text { Usulután }\end{array}$ & Iglesia & $\begin{array}{l}15 \text { y } 16 \text { de } \\
\text { mayo }\end{array}$ & $\begin{array}{l}\text { Culto orientado a la } \\
\text { abundancia de las } \\
\text { cosechas. }\end{array}$ & $\begin{array}{l}\text { Sombrero de } \\
\text { palma, matata, } \\
\text { chorizos, cuma, } \\
\text { tecomate, cruz. }\end{array}$ & $\begin{array}{l}\text { Danza de los } \\
\text { Tabales, misas } \\
\text { novenarios, } \\
\text { procesión. }\end{array}$ \\
\hline
\end{tabular}


San Rafael

Oriente, San

Miguel

Miguel

Culto

familiar

Día de

pentecostés.

Cantón

La Presa,

Usulután

Santa Elena,

Usulután
Ya no

24 y 25 de

Culto
familiar $\quad 16$ de mayo

existe
Culto orientado

a la sanación

de enfermos en

general.

Culto orientado

Culto orientado a

la agricultura y la

salud de los niños.

a pagar diversos

tipos de peticiones.

\section{Sombrero de}

palma, matata,

listón rojo,

tecomate y

cruz.

Ninguno. La

imagen es

la que más

representa a

Ios africanos

esclavizados.

Sombrero de

palma y cruz.
Danza de

Ios Tabales, relaciones, misas, novenarios, procesión.

Danza de los Tabales, donde utilizan trajes especiales, rezos, novenarios y altar.

\section{Las Zapatetas}

o Danza de los

Tabales, rezos, novenarios y altar.

Danza de los

Tabales, rezos, novenarios y altar.

Cuadro 1. Cuadro resumen de los elementos rituales del culto a San Benito de Palermo en la zona oriental de El Salvador. Elaborado basado en el trabajo de campo de la investigación por, Marielba Herrera, 20011

\section{Consideraciones finales}

La historiografía centroamericana ha abordado la temática de los afrodescendientes para el istmo centroamericano. De tal cuenta que la mayoría de estudios sobre la ascendencia africana en El Salvador han sido vistos e investigados desde la óptica de la historia. Otras ciencias sociales, poco han desarrollado dicho tópico. Esta exploración formula la contribución de investigar a los afrodescendientes salvadoreños desde la antropología, desde la historiografía y especialmente desde el estudio de una práctica religiosocultural.

El culto a San Benito de Palermo, es una de las expresiones con elementos culturales afrodescendientes que se mantienen vigentes en la zona oriental del El Salvador. Cada uno de ellos representa la forma en que estos grupos realizaban sus prácticas religiosas dentro de la antigua provincia de San Salvador y del curato de Ereguayquín. Estas formas de organización y reunión, desde lo subalterno, permitía expresar una resistencia social y participación dentro del entorno donde se desenvolvían, probablemente surgidas en contextos del cimarronaje; otras llegaron a ser reconocidas por la Iglesia católica. Por tanto, eran cultos públicos donde los negros esclavizados y afrodescendientes vieron una oportunidad de estatus social.

Así sucedió con las cofradías de negros establecidas en San Salvador y Usulután. Estas se establecieron en la época colonial y desaparecieron con el tiempo. Cabría la posibilidad de que muchas de las funciones de los miembros de dichas asociaciones fueran similares a las que se tenían en otros lugares con análogas características étnicas, religiosas, económicas y políticas.

Por su parte, el culto privado adquiere una connotación subalterna que se mantiene hasta la fecha en los pueblos que formaban, en su momento, parte del antiguo Curato de 
Ereguayquín. En la actualidad, estos mismos poblados abren espacios para los devotos locales, comparten una tradición familiar que está compuesta de los mismos elementos que el culto público; sin embargo, no cuentan con el recurso económico de instituciones para sus festejos. Dichas limitantes llevaron a un ritual privado, donde las prácticas "ocultas" permitieron que se mantuvieran los elementos tradicionales de la cultura africana. Esta idea de lo subalterno les permite, como en el pasado, tener un sentido de pertenencia e identidad como grupo social excluido.

Para ambas tradiciones — la pública y la privada—, la imagen del santo negro refleja las realidades del campesinado, su condición de trabajadores del campo. Es por esa razón que la mayoría de San Benitos de Palermo han sido adaptados por la comunidad y portan elementos como el sombrero, la matata, el tecomate y otros que potencializan la identidad campesina y seguramente del campesinado mulato de la región, el cual se vio implicado de manera significativa en la producción ganadera y agrícola de las haciendas añileras; justamente como lo demuestran las fuentes historiográficas centroamericanas que abordan el tema de la producción agrícola en la época colonial.

En general, se trata de rituales de petición, ya sea por abundancia de los productos agrícolas, la salud u otros favores donde es importante tomar en cuenta las condiciones sociales, culturales, económicas y políticas que dieron forma a estas expresiones que se actualizan y renuevan con el tiempo, pues estas son el resultado de reproducir aspectos pasados, reales o inventados, que pueden ser innovados o reinventados, siempre y cuando estas modificaciones respondan a elementos similares que permitan la continuidad social.

Esta tradición busca inculcar valores y normas de comportamiento a través de la práctica dentro del contexto social en el que surgió. Quizá en este último elemento no estén tan claros con los diferentes grupos étnicos que con el tiempo dieron forma al culto, a la imagen $y$, a su vez, a la Danza de los Tabales; prácticas que reflejan la diversidad étnica que ha sido negada, producto de un blanqueamiento mental y que lo expresan sus devotos cuando se refieren a la imagen de San Benito de Palermo como "un hombre del campo que trabajaba en el campo, por eso se volvió negro".

\section{Referencias}

Bernand, C. (2001). Negros esclavos y libres en las ciudades hispanoamericanas. Madrid. Fundación Histórica Tavera.

Cáceres, R. (2008). Los silencios en nuestra historia. En: Del olvido a la memoria: africanos y afromestizos en la historia colonial de Centroamérica, pp. 9-15. Editado por Rina Cáceres Gómez. Oficina regional de la Unesco, San José, Costa Rica.

Giménez, G. (2010). Entre lo público y lo privado. La continuidad de las expresiones culturales afroporteñas (1820-1852). Revista Digital Estudios Históricos. No. 4. Centro de Documentación Histórica del Rio de la Plata y Brasil. Uruguay.

Gutiérrez, I. (2011) Las cofradías de negros en la América hispana. Siglos XVI-XVIII. África Fundación Sur [En línea] España [Consulta: 13 de octubre de 2011] Consultado en: http://www. fundacionsur.com/spip.php?article2293

Lokken P. \& Lutz C. (2008). Génesis y evolución de la población afrodescendiente en Guatemala y El Salvador (1524-1824). En: Del olvido a la memoria: africanos y afromestizos en la historia colonial de Centroamérica, pp. 16-36. Editado por Rina Cáceres Gómez. Oficina regional de la UNESCO, San José, Costa Rica.

Loucel, C. (2011) La invisibilización de la población afrodescendiente en El Salvador. En: Poblaciones negras en América Central. Cuaderno de trabajo No. 10. México. Marzo de 2011.

Montes, S. (1976). Etnohistoria de El Salvador. El Guachival centroamericano. Tomo II. Dirección de Publicaciones, Ministerio de Educación.

Roselló, E. (2008). Iglesia y religiosidad en las colonias de la América española y portuguesa. Las cofradías de San Benito de Palermo y de Nuestra Señora del Rosario: una propuesta comparativa. Dossier: virreinatos. Marzo-abril. Año 3, número 14. México. Pág. 336-553.

Sánchez, R. (2001). La observación participante como escenario y configuración de la diversidad de significados. En: María Luisa Tarrés, Observar, escuchar y comprender sobre la tradición cualitativa en la investigación social. Flacso y El Colegio de México, México.

Vila, E. (2000). La evangelización del esclavo negro y su integración en el mundo americano. En: Berta Ares Queija y Alessandro Stella (coords.) Negros, mulatos y zambaigos. Derroteros africanos en los mundos ibéricos. Sevilla: EEAH. 2000. pp. 189206. 